\title{
20 DESIGN FOR PRODUCT LIFECYCLE MANAGEMENT
}

\author{
Wenlei Zhang ${ }^{1,2}$, Yushun Fan ${ }^{3}$ \\ 'Shenyang Institute of Automation, Chinese Academy of Sciences, Shenyang, P.R. China, \\ ${ }^{2}$ Gradute School of the Chinese Academy of Sciences, Beijing, P.R. China, zwl@sia.cn \\ ${ }^{3}$ Dept. of Automation, Tsinghua University, Beijing, P.R. China, fanyus@tsinghua.edu.cn
}

\begin{abstract}
Product lifecycle management (PLM) is a concept that aims at integrating the various processes and stages involved during a typical product lifecycle for the extended enterprise. PLM technologies endeavor to offer a powerfin collaborative platform to support distributed product development. In order to maintain the integrity of product definition data throughout the life of the product, and to manage business processes used to create, manage, disseminate, share and use the information, this paper first explores the connotations of PLM; then presents a conceptual modeling framework including a four-tier-architecture; furthermore models product lifecycle in the stages of requirement analysis, conceptual design, engineering design, manufacturing and services; and finally proposes an integration framework to support interoperability of distributed product data sources.
\end{abstract}

\section{INTRODUCTION}

The Product Lifecycle Management (PLM) concept holds the promise of seamlessly integrating all the information produced throughout all stages of a product's lifecycle to everyone in an organization at every managerial and technical level. Most of global leading providers and consultant organizations of manufacturing automation solutions, including UGS, IBM, PTC and CIMdata etc, consider PLM is the key to collaboration and cooperation. "The strategy of PLM is to build up extended enterprise based on web and support all the suppliers, partners and trusted customers to capture, manage, evaluate and utilize all the related information." [1]

As the backbone of PLM approach, product information model enable the description, dissemination and sharing of product data in the distributed manufacturing environment. So, the product modeling technologies have won the extensive recognition in both academia and industry. In the last two decades, product modeling technologies for specific stages have been enormously explored. Bidarra and Brownsvoort give the product engineering design models based on semantic featuring modeling technology ${ }^{[2]}$. Jiao offers a generic bill-of-material and operation (GBOMO) data model to manage variant product structures of the product family ${ }^{[3]}$.Simon presents a product lifecycle data acquiring technology (LCDA), which employs sensors and micro-processors to collect product operation process 
data dynamically to build product operation data model ${ }^{[4]}$. Shehab etc. presents a knowledge-based intelligent product cost evaluation system, which helps designers evaluate product manufacturing cost ${ }^{[5]}$.

With the increasing competition in the global market, the manufacturing industry need make agile responds to changes of market. Modes of enterprises federation, web manufacturing and collaborative manufacturing demand enterprises adopt information technologies to maintain and management distributed product data uniformly ${ }^{[6]}$. And product lifecycle model offers a conceptual mapping mechanism for them to link data of product design, process, quality, cost, sales and operation. And it allows the related distributed data to be acquired and processed. The Axiomatic Design (AD) method proposed by Suh is one such approach that provides a systematic lifecycle guideline for evaluating the acceptability of designs ${ }^{[7]}$. In AD, the design process is considered a series of domains and their mappings, and the domains mainly include: $\{\mathrm{CSs}\},\{\mathrm{FRs}\},\{\mathrm{DPs}\}$ and $\{\mathrm{PVs}\}$. Jiao and Tseng further establish the FBS-views product model ${ }^{[8]}$, and the mappings among the views push the product variant design along the product lifecycle. And bill-of-materials can represent the product information by a common and simple data format ${ }^{[9,10]}$. Single Source of Product Data (SSPD) is presented to explore the logic relations of product data, aiming to build a logic uniform data source of physically distributed product data, so the access and operation of product data can be derived from the single source ${ }^{[11]}$. And web-based product lifecycle modeling technologies have been broadly researched ${ }^{[12-13]}$

But PLM solutions stress that product data should be created, exchanged and shared across all the stages along the product lifecycle. And the definition and management of a global product information model is the key to implement PLM. However, the above modeling technologies have been rare researched. So this paper devotes to exploring the approaches of building an integrated, reconfigurable and consistent product lifecycle information model, which is addressed by the framework of global PLM model, stage models and their evolution modes.

\section{THE PLM DEFINITION AND SYSTEM ARCHITECTURE}

CIMdata gives the classic definition of PLM as: (1) A strategic business approach that applies a consistent set of business solutions that support the collaborative creation, management, dissemination, and use of product definition information; (2)

Supporting the extended enterprise (customers, design and supply partners, etc.); (3) Spanning from concept to end of life of a product or plant; (4) Integrating people, processes, business systems, and information. ${ }^{[1]}$

We present our understanding of PLM values as Figure 1 shows, and this figure shows that

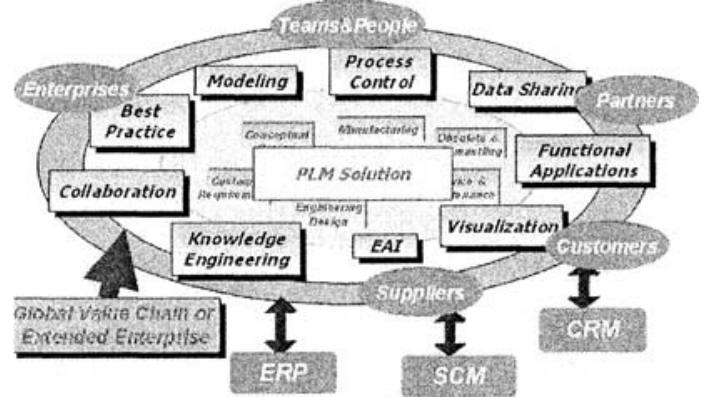

Figure 1 - Collaborative platform of PLM 


\begin{tabular}{|l|l|l|l|l|l|}
\hline & Industry-wide Solutions & Customized Solutions & $\cdots$ \\
\hline & Product Models & Process Models & Enterprise Models \\
\hline
\end{tabular}

Figure 2- System Architecture of PLM

PLM solutions endeavor to encapsulate foreign data, processes and heterogeneous information systems. So a collaborative platform is built up for the global value chain to create and share knowledge assets.

Based on elaborate researches on the related cases, solutions and literatures, we build up system architecture of PLM solution as Figure 2 shows.

So the following sections of this paper will discuss a conceptual modeling framework dedicating to resolve these core problems. This framework demonstrates the mechanism to create and transform data across each stage along the product lifecycle, while keeping data integrity and smooth processes.

\section{GLOBAL PRODUCT LIFECYCLE MODEL}

We divide the product lifecycle into 5 main stages, as Figure 3 shows: (1) requirements analysis, to capture and analyze customer requirements (CRs); (2) conceptual design, to develop a conceptual product plan; (3) Detailed design, to design parts, assemblies and product structure etc.; (4) manufacturing, to produce the product; (5) services, to offer the technical support, maintenance, overhaul and repair for products.

These 5 stages are not segregated from each other, but overlapped or intertwined partly. For example, in detailed design stage, the engineers may need to collaborate

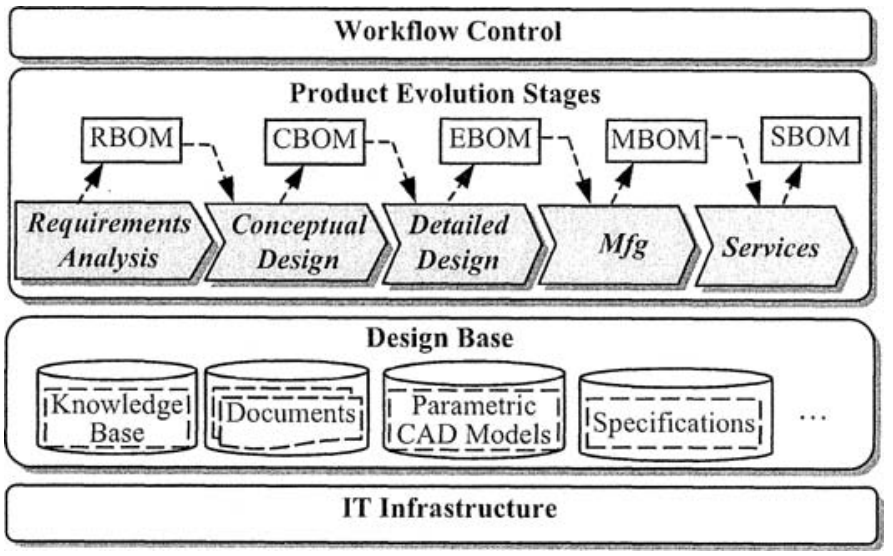

Figure 3-Global product lifecycle model 
with customers to acquire clear requirement.

And the integral flow of data and businesses are consistently created and evolved along this life line. Each stage contributes to this flow. BOMs can be easily read and stored by database systems, so most of formats of data and files are organized and indexed by them. Most of their data can be partly or totally derived form the design base, which affords single source of product data for knowledge reusing. And the product evolution flow needs to be controlled by workflow system, so the businesses can be triggered and performed automatically. IT infrastructure includes hardware, software, and Internet technologies, underlying representation and computing languages, and distributed objects and components.

\subsection{Requirements Analysis}

To capture and understand customer needs effectively and subsequently transfer them to design specifications is one of essential premises for successful product design ${ }^{[14]}$. As the initial stage of the product lifecycle, Requirements analysis aims to transform the product from the customers' viewpoint to the designers' one.

Figure 4 shows the model of requirements analysis in three processes:

(1) Capturing, the requirements can be addressed in terms of "Information", "Features" and "Sketches". (1) "Information" is designed to capture general CRs like customer features, main functions, and general needs etc; (2) "Feature" means engineering $\mathrm{CRs}$, which needs customers to collaborative design with enterprises to describe the sizes of parts, assembling conditions or process demands etc; (3) "Sketch" describes technical CRs by means of a serial of sketches, addressing the functional or technical view of the product in the customer's mind.

(2) Translation, the original requirements data need to be quantified, evaluated and transformed to formal CRs specifications, which are organized by RBOM-

Requirements BOM. QFD-quality functions deployment and AHP- analytical hierocratic process are the routine methods to analyze requirements quantitatively.

(3) Management, the CRs should be managed along the product lifecycle to ensure that the product is the exact one customer needs, and make agile responses to the CRs changes.

Web-based configuration, realtime conference and 3D collaborative design are the

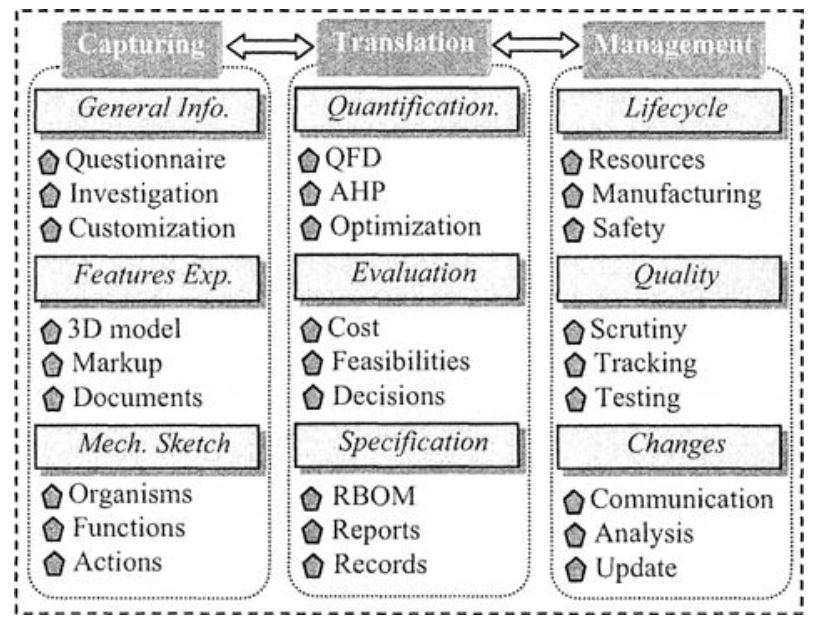

Figure 4 - Requirements analysis model 
necessary tools to support CR analysis. And this stage can derive questionnaire templates, CR topology structure, functional and structural data of product and customer models from the design base.

\subsection{Conceptual Design}

Conceptual design is responsible for the project design to transform CRs specifications to a systematic product developing specification. This specification decomposes the design tasks, schedules and resources according to the CRs. And conceptual design is the key to innovation and production efficiency and effectiveness ${ }^{[15]}$.

As Figure 5 shows, a conceptual product structure need to be constructed in the functional, technical and physical view. The decomposition tree of product functions is closely related to RBOM and generated by mapping CRs to functional modules of

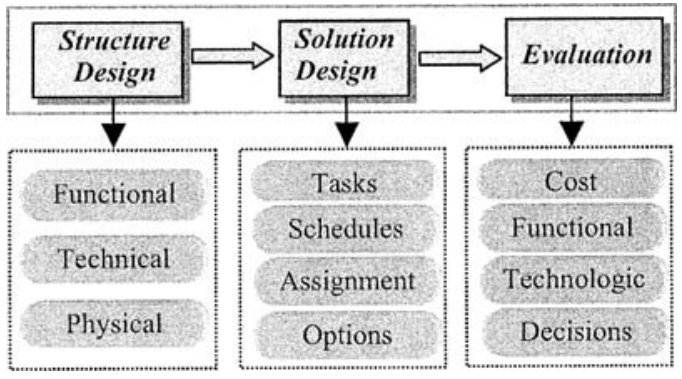

Figure 5 - Conceptual design model product family. Then based on the knowledge and matching rules in technical domain, the design parameters (DPs) coupling to each functional module is deduced, and finally a technical view is derived. By seeking assemblies, components or parts to satisfy these DPs, the physical product structure can be formed.

And generic product structure, components or parts base, configuration rule base function as the design base. Further, the technical tasks of design, manufacturing and services need to be specified according to the conceptual product structure. There are perhaps a set of conceptual product solutions, and each of them is designed for specific consideration. These solutions describe the product developing scheme in terms of tasks, targets, engineering demands, schedules and arrangements etc. and the cost, feasibilities and difficulties of these optional solutions should be evaluated for decision. And a conceptual product BOM (CBOM) affords as a design specification for the downstream stages.

\subsection{Detailed Design}

Most of the new products are designed by resorting to existing technologies or similar products. Modular and structured design methodologies are a deliberate attempt to reduce product development cycles. In fact, if properly used, methodologies provide much more than incremental improvements in products, described as discontinuous jumps in a product's evolution s-curve. Now modularity, product platform and product family architecture are extensively accepted as the basis for unburdening the commonality and the knowledge from the product design and process ${ }^{\lfloor 16\lfloor 17 !}$. 
So we present a product family architecture model that can best satisfy the above demands. As Figure 6 shows, platform, modules, structure and domains are the essentials to address the PF and the product design based on it.

(1) Modules, within the module, a collection of components or parts are closely integrated and form a physical building block, which bears the standard interface and implements specific functions.

(2) Platform, a platform is constructed by key modules and bears the key technologies, product line policies and market strategy of a product family. A platform acts as the common architecture of the related product family, so by plugging the different functional modules into it, diversified products can be easily derived even though they possess the same core-platform.

(3) Structure, a generic product structure is responsible for organization of all the related data and files of a product

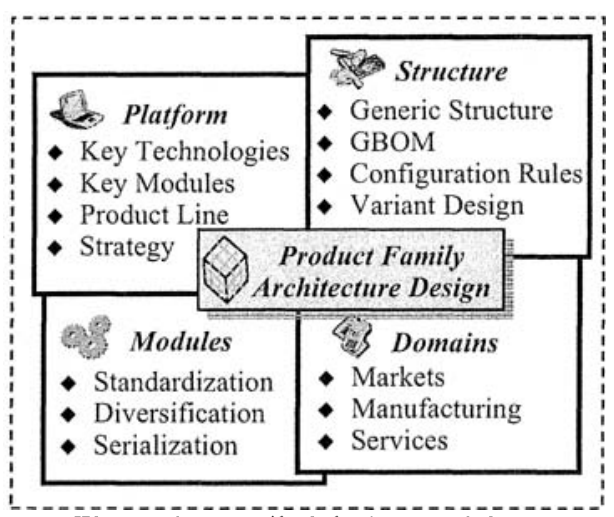

Figure 6 - Detailed design model family. And all modules are classified according to their interrelationships and assigned as nodes in the generic product structure tree. GBOM- generic BOM expresses the data relationships of this generic structure in different views such as functional GBOM and engineering GBOM etc.

(4) Domains, Domains are special data views covering each stage of product lifecycle. So the knowledge base for each stage is unburdened to form the foundation and mechanism, and it can be reused and reconfigured to produce the new products along the lifecycle.

Based on this model, product design takes different forms: ATO - assemble to order, ETO - engineering to order, MTO - manufacturing to order, and RTO research to order. To ATO/ETO/MTO, it would be easier to design products by customization or partly modification based on PF architecture.

To RTO, a totally new product needs to be developed from the beginning. And this new product can grow to be a new product family. Following the conceptual design, the detailed design tasks are mostly focused on the modules and their last assemblies. The Figure 7 illustrates the modules design mode. 
And an EBOM-engineer BOM will be produced to transfer the engineering data to the next stage.

\subsection{Manufacturing}

In manufacturing stage, a physical product is gradually produced and assembled based on the detailed design specifications. Three intertwined essential flows string all the activities and functions of this stage, including information flow, material flow and energy flow. A P3R (Product - Process - Plant - Resources) integrated model is presented as Figure 8 shows, which attempts to support concurrent development, manufacturing and production processes.

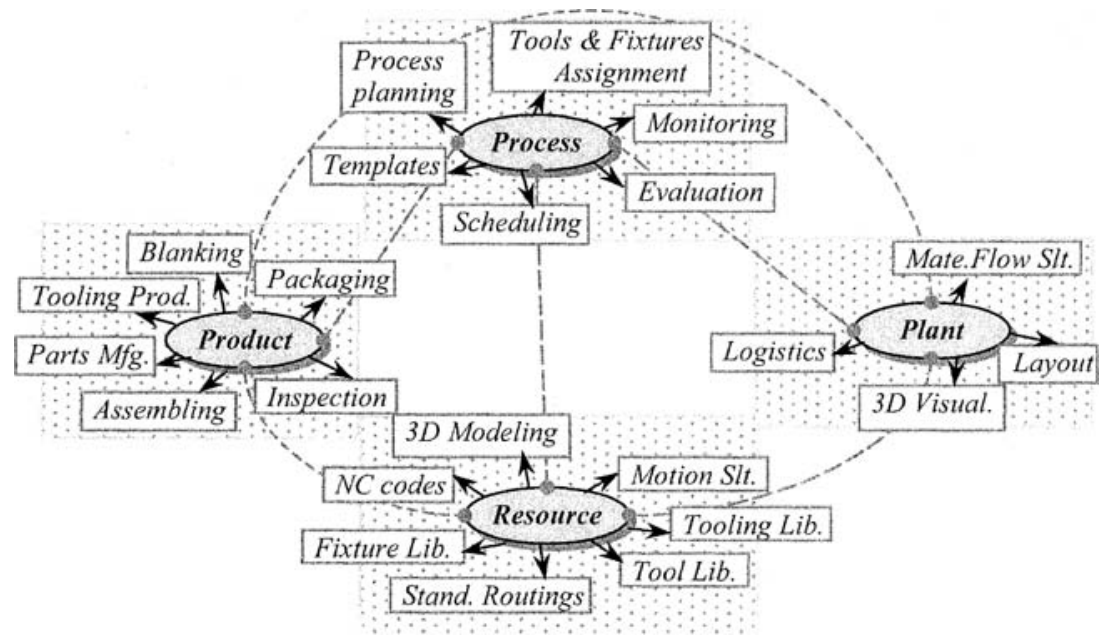

Figure 8 - Manufacturing model

In addition to managing the data lifecycle of the product components and assemblies, P3R model can help manage the processes of manufacturing product assemblies, machining individual components, laying out the facility in which the process will be executed and deploying the resources used by the processes.

MBOM - manufacturing BOM is produced to manage the manufacturing data.

\subsection{Services}

As the final stage of product lifecycle, especially after delivering products, the services of technical support, maintenance, repair and overhaul need to be offered for customers. And they can be performed or managed based on a common base, which is a part of the design base.

This common base can be modeled as Figure 9 shows, which mainly includes five sections: platform, knowledge, resources, for-services data and services modules.

(1) Services platform, the strategies, policies, common solutions and core data of services are drawn out and designed here. And the services for product variants can be derived from it ${ }^{[18]}$. 
(2) Services modules, Parts and components are marked with the services properties, which are accessories, alternate, reclaimable and standard. Services modules also include modular services contents such as the training courses and manuals, so enterprises can reuse them across the product families and along the product line.

(3) For-services data, the services data can be addressed by Services BOM, which may be a series of BOMs due to the complexity of the services. For instance, manufacturers need a dismantling BOM for the dismantling and reclaiming process after products retired.

(4) Resources, the services resources store and manage e-files of manuals, the records of the customers and their purchasing reports and services $\log$ etc. and even the

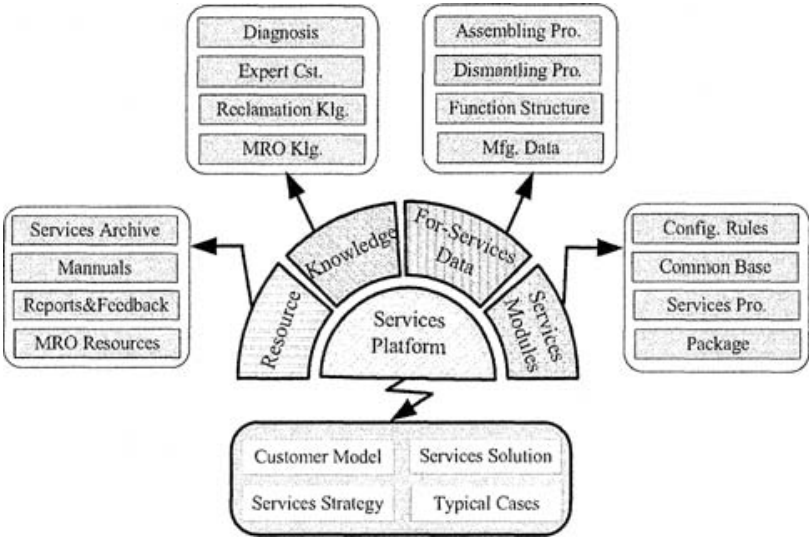

Figure 9 - Services model repair tools and equipments can be classified as resources. Customers and companies can get supply from this base for the services.

(5) Knowledge, the common knowledge may be offered for customers to deal with the difficulties or problems from the products practicing, such as FAQs or online diagnosis system. For the special products, enterprises may need expert systems to analyze the troubles. And to MRO and green manufacturing, knowledge plays a very important role.

\section{A J2EE BASED PLM PROTOTYPE SYSTEM}

Based on the above product lifecycle modeling framework, we developed a J2EE based PLM system, i.e. Tornado PLM, which is now successfully adopted by several Chinese manufacturing enterprises.

Tornado PLM employs an integration framework based on J2EE, as Figure 10 shows. It intends to unlock essential

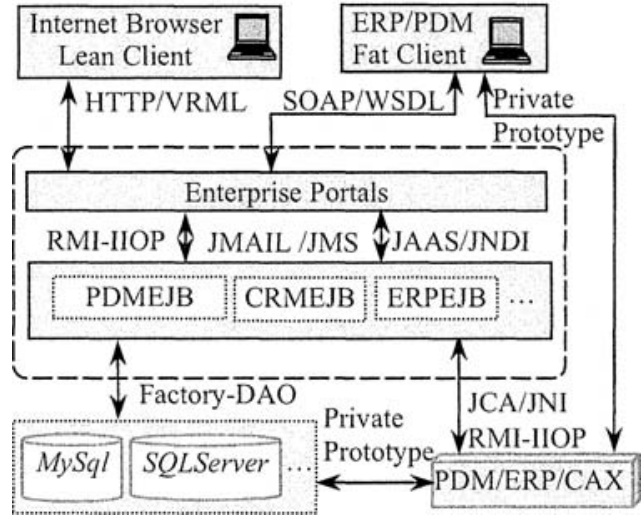

Figure 10 - A J2EE based integration framework 
information within core business systems (PDM, ERP, CRM, CSM) across the entire value chain providing the product centric data integration of disparate systems along with PLM centric functionality \& behavior.

By Tornado, designers can accomplish web based product lifecycle developing from customer requirements capturing to product services support. And Figure 11 gives an interface of this system for illustration.

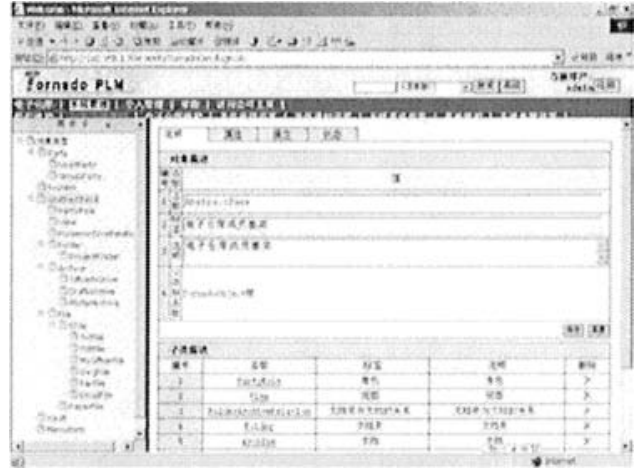

Figure 11 - Tornado PLM system

\section{CONCLUSION}

The PLM concept promises to provide support for the product's entire lifecycle, from the product requirements to the disposal of its last instance. The volume, diversity, and complexity of information describing the product will increase correspondingly.

This paper makes a proposal for a conceptual framework for product lifecycle modeling that can manage, generate, serve, and reuse all the product information throughout the entire lifecycle. We divide the product lifecycle into five main stages: requirement analysis, conceptual design, detailed design, manufacturing and services. All these stages are discussed in order to demonstrate the consistent business and data flow evolved across the product lifecycle. Methodologies for producing and management of the product information and businesses are presented. And especially we intend to develop a common base that can support single, steady, uniform and consistent product lifecycle developing. And a J2EE based integration framework is proposed for collaborative product development.

\section{ACKNOWLEDGEMENT}

This paper is funded by the Major State Basic Research Development Program of China (973 Program), No. 2002CB312200.

\section{REFERENCES}

1. CIMdata, "Product Lifecycle Management, Empowering the Future of Business", www.cimdata.com, 2002.

2. Bidarra R, Brosvoort WF. Semantic feature modeling. Computer-Aided Design, 2000, 32: 201-225.

3. Jiao JX, Tseng MM, Ma Q, et a1. Generic Bill of Materials and Operations for High Variety Production Management. Concurrent Engineering: Research and Applications, 2000, 8(4): 297-321. 
4. Simon $M$, Bee G, Moore $\mathrm{P}$, et al. Modeling of the life cycle of products with data acquisition features. Computers in Industry, 2001, 45: 111-122.

5. Shehab EM, Abdalla HS. Manufacturing cost modeling for concurrent product development[J]. Robotics and Computer Integrated Manufacturing, 2001, 17: 341-353.

6. Rezayat M. The enterprise-web portal for life-cycle support. Computer-Aided Design, 2000, 32:85-96.

7. Suh NP. The Principles of Design. New York: Oxford University Press, 1990.

8. Jiao JX, Tseng MM, etc. Product family modeling for mass customization. Computers ind. Engn, 1998, 35: 495-498.

9. Trappey AJC, Peng TK, Lin HD. Object-oriented bill of materials system for dynamic product management. J Intelligent Manufacturing, 1996, 7(5): 365-371.

10. Du J, Gu P, Jiao Y. Generic BOM processing system for Assembly-to-order production. Journal of Systems Science and Systems Engineering, 2001, 10(1): 1-6.

11. Glowen R. DCAC/MRM paves way to simpler production system. Boeing Frontiers Online, December 2003. http:/www.boeing.com/news/frontiers/archive/2003/december/i_ca2.html

12. Wang $\mathrm{CE}$, $\mathrm{Chu} \mathrm{CB}$, Yin $\mathrm{CW}$. Implementation of remote robot manufacturing over Internet. Computers in Industry, 2001, 45(3): 215-229.

13. Rezayat M. Knowledge-based product development using XML and KCs, Computer-aided design, 2000, 32: 299-309.

14. Tseng MM and Jiao JX. Computer-Aided Requirement Management for Product Definition: A Methodology and Implementation. Concurrent Engineering: Research and Application, 1998, 6(3), 145-160.

15. Tay FEH and Gu JX. "Product Modeling for Conceptual Design Support", Computers in Industry, $2002,48(2), 143-155$.

16. Jiao JX, Tseng MM, Dufty VG and Lin F. "Product Family Modeling For Mass Customization", Computers ind. Engn, 1998, 35(3-4), 495-498.

17. Meyer MH and Lehnerd AP. The Power of Product Platforms: Building Value and Cost Leadership, The Free Press, New York, USA: 1997.

18. Zhang WL and Fan YS. "Extending Product Family Approach to Support Services", Proceedings of the Second IEEE International Conference on Services Systems and Services Management, Beijing, P.R. China, June. 4-7, 2005, pp. 735-740. 